\title{
Enhanced exposure of subvalvular structures during mitral valve repair with a novel flexible and reusable leaflets retractor
}

\author{
Igor Tudorache, MD, and Axel Haverich, MD, Hannover, Germany
}

\footnotetext{
From the Department of Cardiothoracic, Transplantation and Vascular Surgery, Hannover Medical School, Hannover, Germany.

Disclosures: Dr Tudorache was involved in the development of the product, discloses a financial relationship with Fehling Instruments $\mathrm{GmbH}$, and has no conflict of interest for this manuscript. Dr Haverich has nothing to disclose with regard to commercial support.

Received for publication Dec 7, 2017; revisions received Jan 25, 2018; accepted for publication Feb 12, 2018; available ahead of print March 8, 2018

Address for reprints: Igor Tudorache, MD, Department of Cardiothoracic, Transplantation and Vascular Surgery, Hannover Medical School, Carl-Neuberg-Str. 1, Hannover 30625, Germany (E-mail: tudorache.igor@ mh-hannover.de).

J Thorac Cardiovasc Surg 2018;156:643-5

$0022-5223 / \$ 36.00$

Copyright (c) 2018 by The American Association for Thoracic Surgery

https://doi.org/10.1016/j.jtcvs.2018.02.036
}

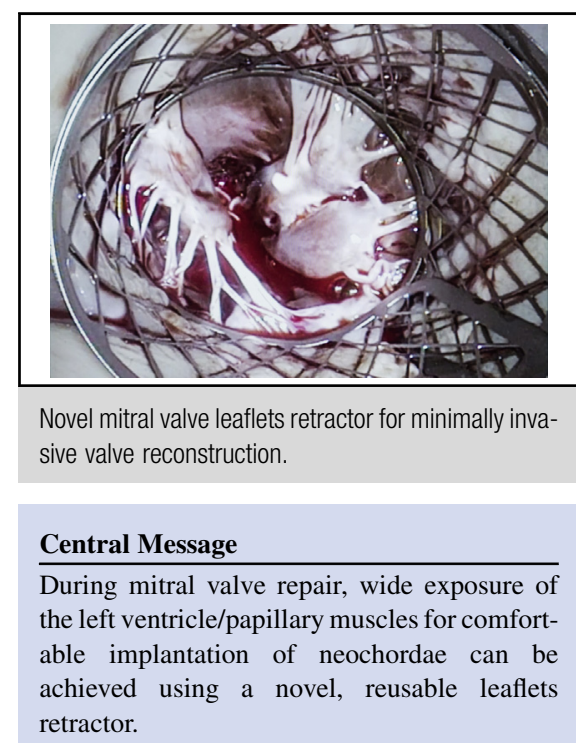

See Editorial Commentary page 646.
In degenerative mitral valve surgery, mitral valve repair can be performed with very low mortality $(<1 \%)$ and offers a postoperative survival similar to the expected age- and sex-adjusted general population. ${ }^{1}$ An important step of the valve reconstruction involves removal of the pathologic leaflet segment and/or resuspension of the loose leaflet segment on an adequate papillary muscle with the use of artificial chordae. ${ }^{2}$ Exposure of the papillary muscles, particularly through a minimally invasive approach, can sometimes be challenging, especially in cases characterized by excess of leaflet tissue. Here we present a novel leaflets retractor manufactured from nickel-titanium alloy developed for easy introduction through the mini-thoracotomy and precise placement within the mitral valve annulus.

\section{TECHNIQUE}

In our clinic, the right mini-thoracotomy is the access of choice in all cases with isolated mitral or/and tricuspid valve pathology. Since August 2016, we have routinely used the retractor. After exposure of the mitral valve and inspection of the valve pathology, the leaflets retractor can be placed. For this, the flat retractor $(0.12 \times 25 \times 200 \mathrm{~mm})$ (Figure 1, A) can be easy rolled to a cylindrical form with a diameter of $15 \mathrm{~mm}$ and then grasped with a long needle holder (Figure 1, B). Like this, it may be introduced through the mini-thoracotomy and inserted into the mitral valve annulus. Initially, once released from the needle holder,
Video clip is available online.

the retractor opens spontaneously within the annulus and if required, can be easily de-rolled/adjusted up to maximal diameter of the valve annulus by using additional long forceps (Video 1). Subsequently, both leaflets are pushed to the sides and exposure of entire subvalvular apparatus is achieved (Figure 2). Implantation of neo-chordae can be comfortably performed on one or several papillary muscles. Afterwards, the retractor can be removed by simple pulling on one retractor end (Video 1). Finally, artificial chordae are fixed to the free edge of the leaflet in any convenient manner.

\section{COMMENT}

Placement and release of new retractor, with normal minimally invasive instruments, is simple and convenient for the surgeon. It does not require additional devices or fixation tools and does not produce additional surgical trauma. Moreover, introduction and complete deployment requires only seconds and does not impact ischemia time.

The idea is not novel, and several facilitating tricks or special devices have been already proposed for this reason. Dr J. Lamelas developed a comparable commercial device (COLLAR Papillary Muscle Exposure Device; Miami Instruments, Miami, Fla). However, it is a disposable device 


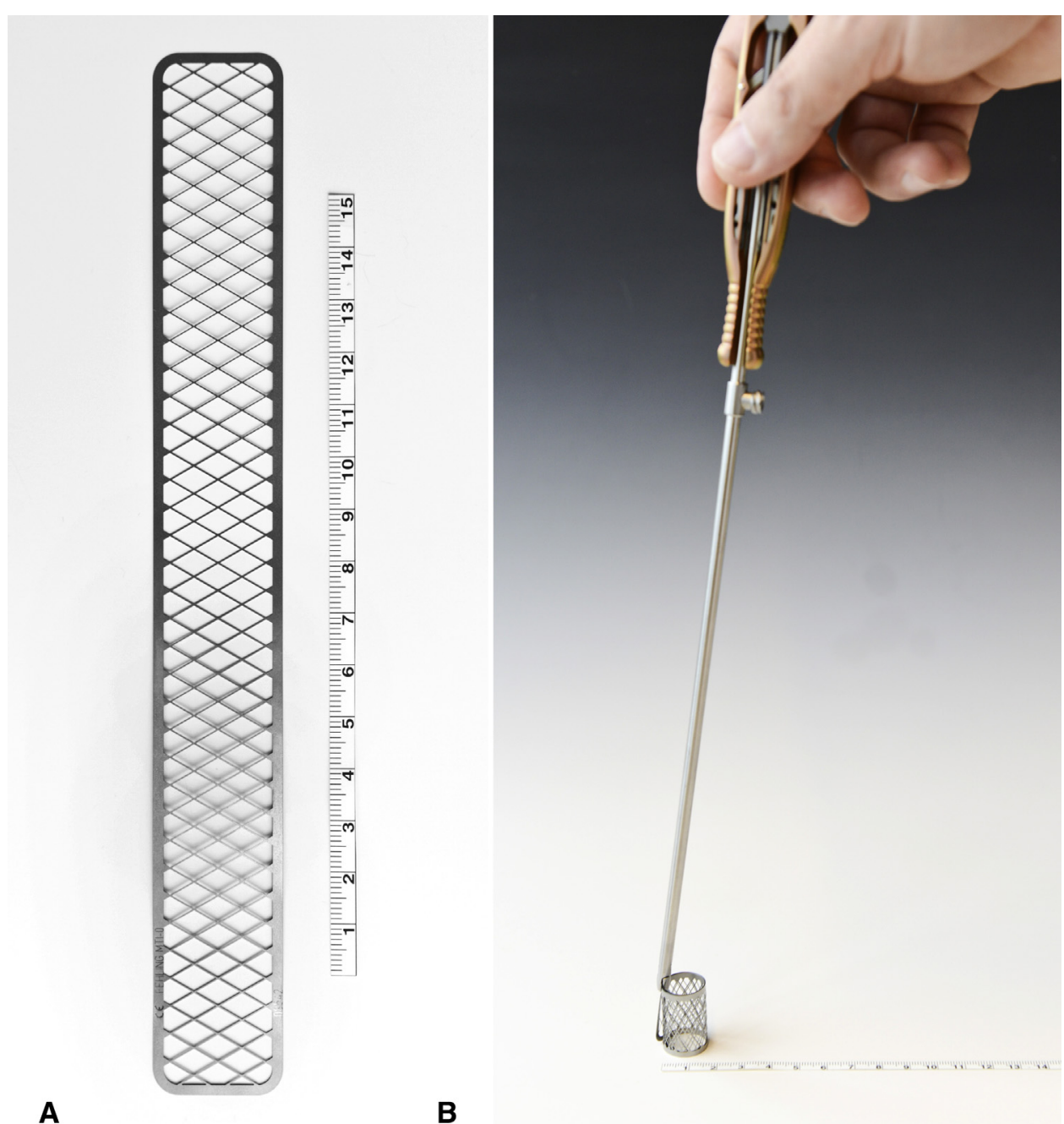

FIGURE 1. Mitral valve leafleats retractor for minimally invasive surgery, in the unmanipulated flat form (A) and in the cylindrical form held with a needle holder (B).

that increases the costs of the procedure. Our retractor, in comparison, can be sterilized and was designed as a fine metal grate/mesh to allow it to remain easily fixed within the annulus. In addition, it allows the visualization of the structures pushed under retractor. This allows visualization of native chordae during implantation of the neo-chordae

\section{before}

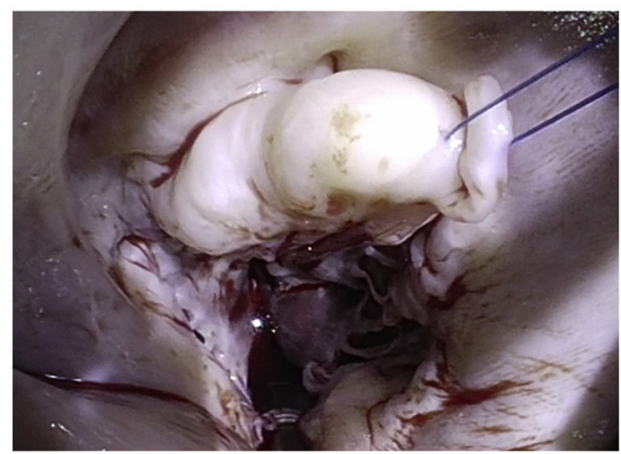

after

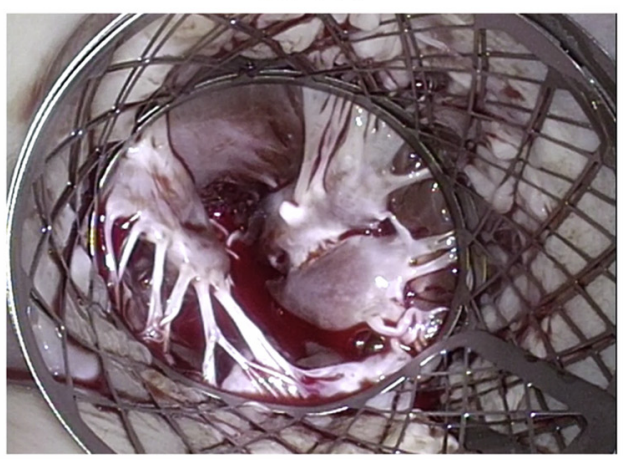

VIDEO 1. Minimally invasive mitral valve reconstruction with implantation of neo-chordae using the novel mitral valve leaflets retractor. Video available at: http://www.jtcvsonline.org/article/S0022-5223(18)30401-X/fulltext. 


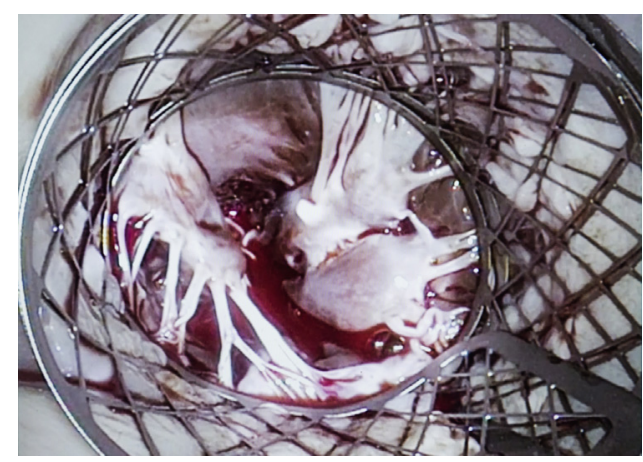

FIGURE 2. Mitral valve leafleats retractor placed within the annulus, allowing visualization of the left ventricle and papillary muscles.

and helps for their correct distribution on the appropriate papillary muscle depending on insertion of the neighborhood native chordae. Furthermore, because of its flexibility, the retractor can even be placed within an alreadyimplanted mitral valve ring, in case of unsatisfactory reconstruction outcome and need for implantation of additional neo-chordae.

Erlebach and colleagues ${ }^{3}$ suggested the off-label use of a commercially available valve sizer for aortic valve prostheses introduced through the mini-thoracotomy. Given that, even the maximal diameter of available sizer-ring for the mitral valve prostheses is $33 \mathrm{~mm}$, the internal area, used as working zone, remains limited to a diameter of $29 \mathrm{~mm}$. Moreover, the sizer ring can reduce or interfere with the working space at the thoracotomy level, as well sometimes require holding/fixation of the sizer during placement of neo-chordae. By using our retractor, deploying to the maximal diameter of the annulus allows achievement of greatest possible working area and thus allows not only comfortable stitching but also grasping of the needle deep within the left ventricle using instruments holding in both hands. Moreover, because of the flexibility of the retractor, deployment to a flat form occurs already intrathoracicaly and allows removal of the retractor without any additional manipulation on the already-implanted artificial chordae. In our experience, as well in international postmarked follow-up, no retractor-related complications have been observed/reported to date.

In conclusion, the use of the new flexible mitral valve leaflets retractor allows excellent exposure of the entire left ventricle, facilitating precise examination of subvalvular structures and comfortable implantation of neo-chordae on the appropriate place of papillary muscle. In our opinion, use of this retractor has a beneficial impact on understanding of mitral valve anatomy thereby, increasing the reproducibility of mitral valve reconstruction and facilitating training of young surgeons.

The authors thank Mrs Ana Junge for her assistance in preparing of images.

\section{References}

1. Coutinho GF, Garcia AL, Correia PM, Branco C, Antunes MJ. Long-term followup of asymptomatic or mildly symptomatic patients with severe degenerative mitral regurgitation and preserved left ventricular function. J Thorac Cardiovasc Surg. 2014;148:2795-801.

2. David TE, Armstrong S, Ivanov J. Chordal replacement with polytetrafluoroethylene sutures for mitral valve repair: a 25-year experience. J Thorac Cardiovasc Surg. 2013;145:1563-9.

3. Erlebach M, Lange R, Mazzitelli D. Placement of neochords in mitral valve repair: enhanced exposure of the papillary muscles using a standard valve sizer. Ann Thorac Surg. 2016;101:378-80. 